\title{
Pais adolescentes: vivência e significação
}

\author{
Zeidi Araujo Trindade \\ Maria Cristina Smith Menandro \\ Universidade Federal do Espírito Santo
}

\begin{abstract}
Resumo
Foram investigadas mudanças ocorridas na vida de pais adolescentes e identificados os significados da paternidade e da maternidade para esses jovens. Oito participantes com idades de 16 a 21 anos foram entrevistados com base em roteiro focalizando: mudanças decorrentes da paternidade; significados da paternidade e da maternidade; práticas parentais. Entre as mudanças referidas destacaram-se a perda de liberdade e a inserção no mercado de trabalho. Para eles ser pai significa, principalmente, trabalhar para prover as necessidades da criança e também educar, dar carinho e atenção. A mãe é aquela que cuida e dá carinho, sacrifica-se e é a figura mais importante na vida da criança. As práticas parentais mais mencionadas estavam relacionadas com lazer e brincadeiras. Os dados indicaram a permanência de forte vínculo com os modelos tradicionais de parentalidade, embora tenham mostrado também a emergência de relações afetivas significativas entre pais e filhos.
\end{abstract}

Palavras-chave: Paternidade, Adolescentes, Práticas parentais

\begin{abstract}
Teenage fathers: Life experience and signification

Changes occurred in the life of teenage fathers and the meaning of fatherhood and motherhood for these adolescents were investigated. Eight participants sixteen to twenty-one years old were interviewed with directions focusing: changes arising of paternity; meanings of fatherhood and motherhood; parental practices. Among the changes referred figured the loss of freedom and the insertion in the job market. For them, to be a father means, mainly, to work to provide the needs of the child and also to educate, give comfort and attention. The mother is the one who cares and caresses, makes sacrifices and is the most important figure in the child's life. The most mentioned parental practices were related with leisure and play. The data indicate the permanence of a strong link with the traditional parenting models, although an emergence of significant affective relations between parents and children was also detected.
\end{abstract}

Key words: Paternity, Adolescents, Parental practices.

A

gravidez adolescente tem se tornado um fenômeno de interesse e preocupação acadêmica, social e governamental. Segundo dados do DATASUS/ FNS/MS (Brasil, 2000) o índice de gravidez nas idades entre 15 e 19 anos chegou a $24,63 \%$ do total de partos realizados no SUS em 1996.

O aumento na freqüência de ocorrência e os possíveis problemas a ela associados justificam a preocupação com a gravidez adolescente, a ponto de ser considerada um problema de saúde pública, o que expõe a insuficiência de abordagens estritamente biológicas e de pla- nejamento familiar para o enfrentamento desse problema (Oliveira, 1998). O crescente interesse de pesquisadores das áreas humanas e sociais pelo assunto tem contribuído para que se alcance melhor compreensão do fenômeno em questão. A consideração de fatores socioculturais envolvidos pode nos levar a uma abordagem do fenômeno que se diferencie do que Lyra (1997) denomina, criticamente, "discurso especializado sobre a gravidez adolescente" (p. 65). Segundo o autor, neste tipo de discurso a gravidez é sempre encarada como um problema, um sério risco à vida futura da adolescente e de seus filhos e suas 
conseqüências são sempre superestimadas: a mãe adolescente e seus descendentes continuarão na pobreza, obterão salários menores, terão menos tempo de escolarização.

Nóbrega (1995) afirma a necessidade de se procurar apreender o fenômeno da gravidez na adolescência situando-o no contexto em que ocorre, através da análise dos valores que circulam no grupo social em que acontece. Em relato de estudo com adolescentes grávidas das classes populares, Nóbrega (1995) constatou que a maternidade, para elas, era considerada como papel privilegiado, além de estar presente em seus planos de vida "ter uma família, marido e filhos, poder se dedicar aos cuidados da casa, ter seu sustento garantido pelo homem provedor: eis, resumidamente, em que consiste uma vida feliz e a plena realização da mulher" (p. 68).

Um ponto importante para o planejamento de pesquisas e ações que tenham como foco a gravidez adolescente é a revisão de concepções e valores em relação ao fenômeno, considerando toda a complexidade de aspectos a ele relacionado. Pode-se citar como exemplos, o desenvolvimento e expressão da sexualidade dos jovens e a construção e valorização desigual dos papéis de gênero em nossa sociedade.

Como apontam Medrado e Lyra (1999), refletindo sobre os enfoques tradicionalmente dados à questão da gravidez na adolescência, esses enfoques "partem de valores e pressupostos, os quais tendem a construir uma série de implicações éticas no desenvolvimento de pesquisas e na atuação junto aos adolescentes" (p. 230), que podem traduzir-se muitas vezes em ações repressivas cujo impacto na sexualidade e reprodução desses jovens deve ser considerado. Outra questão levantada pelos autores é a da importância da participação dos jovens do sexo masculino nessa discussão.

Ao se pensar a gravidez adolescente e, em geral, as intervenções a ela dirigidas, não se deve descartar o fato de que parte dos parceiros das mães adolescentes é adolescente também. Observa-se que tanto dados governamentais quanto dados de pesquisas acadêmicas ou de órgãos não governamentais parecem ignorar a existência de um grande número de adolescentes que se tornam pais.

Lyra $(1997$; 1998) enfatiza a escassa produção sobre o tema e a dificuldade de ter acesso a dados sobre pais adolescentes, sejam eles governamentais ou não, e aponta, a partir disso, a existência de uma espécie de recusa social em reconhecer a paternidade na adolescência, que acaba por se constituir em um não-lugar na sociedade brasileira.

No entanto, pode-se argumentar que a recusa social em reconhecer o lugar do pai não se restringe apenas ao pai adolescente, ainda que neste caso seja agravada. De acordo com Mackey (1996), os estudos sobre a paternidade só ganha- ram relevância a partir dos anos 70 , principalmente em função dos movimentos feministas e do aumento do número de mulheres no mercado de trabalho.

Rodrigues e Trindade (1999) ressaltam ainda que nos estudos sobre psicologia do desenvolvimento das décadas de 60 e 70, o pai é praticamente excluído, sendo a relação mãe-filho privilegiada como a responsável pelo desenvolvimento sadio da criança. A presença do pai, quando verificável, ocorria principalmente em estudos que investigaram os distúrbios causados pela ausência de um dos pais no desenvolvimento infantil.

A partir da década de 70 os estudos começaram mudar o foco de análise. O reconhecimento da importância do pai em relação aos cuidados da criança tornou-se evidente (Boyd, 1985). Mackey (1996) adverte, no entanto, que até a década de 90 as produções sobre paternidade tinham como premissa que "os pais teoricamente são bastante importantes no desenvolvimento psico-social-emocional saudável de seus filhos..." (p. 116), mas que raramente se encontravam trabalhos nos quais as atividades paternas e a relação pai-filhos fossem realmente observadas.

Não foi senão a partir das últimas décadas que os estudos sobre paternidade começaram a enfocar e, principalmente, a observar mais detidamente as novas relações que estavam ocorrendo entre pais e filhos. Desses estudos, vários indicavam o surgimento de um pai cuidador com "uma nova paternidade em que há um envolvimento maior dos homens-pais nos cuidados dos filhos, acentuando as relações de afetos, a subjetividade e a liberdade no relacionamento familiar" (Resende \& Alonso, 1995, p. 67, grifos do autor).

Algumas contribuições sobre a questão de como os homens brasileiros vivenciam sua paternidade foram trazidas por Ramires (1997), cujo objetivo foi a compreensão e a descrição do fenômeno da paternidade do ponto de vista dos pais. A autora constatou, entre todos os 12 pais que foram sujeitos de sua pesquisa, a participação já concretizada na criação dos filhos ou filhas. Tal participação foi relatada como a divisão de tarefas com a esposa e a realização de atividades conjuntas com os filhos. A despeito dessa constatada participação, observou-se em alguns pais uma insegurança a respeito de sua importância e necessidade na vida dos filhos, além de um receio de que a reivindicação do exercício do papel mais efetivo de pai pudesse causar-lhes algum dano. Ramires (1997) concluiu que os homens "ainda conservam representações acerca da maior importância da relação entre mãe-filho/filha e certeza de que nada substitui essa relação, apesar do desconforto crescente que essa representação lhes acarreta" (p. 95).

Buscando investigar possíveis transformações das representações sociais da paternidade e das práticas parentais, 
Trindade, Andrade e Souza (1997) realizaram uma pesquisa com homens que foram pais nas décadas de 60 ou 80 . Concluíram que as representações estavam fortemente impregnadas pelos modelos tradicionais de paternidade e de maternidade, sendo que nos dois grupos de pais prevaleceu a tradicional divisão de papéis, sendo o de provedor para os homens e o de atendimento aos filhos e realização de atividades domésticas para as mulheres. Apontaram ainda que algumas transformações ocorreram, principalmente entre os pais da década de 80 e os de nível de escolaridade superior. Entre as principais diferenças encontradas na comparação dos dois grupos de pais está a ênfase nos aspectos afetivos da relação paifilho por parte dos pais da década de 80 .

Quanto à paternidade adolescente, a produção de conhecimentos no Brasil é quase inexistente, como aponta Lyra (1997), o mesmo se dando nos Estados Unidos, onde a literatura científica sobre os homens adolescentes e a paternidade "é esparsa, ambígua e freqüentemente contribui para conceitualizações estereotipadas" (Weinsten \& Rosen, 1994, p. 724).

Reis (1997) analisou textos de divulgação científica sobre adolescência, gravidez e maternidade, ao longo do período compreendido entre 1930 e 1990, com o objetivo de identificar as condições epistemológicas que propiciaram o surgimento da questão da paternidade adolescente no âmbito das preocupações da Saúde Pública. Em conformidade com a definição proposta pela OMS para adolescentes, Reis (1997) definiu como paternidade adolescente o fato de um indivíduo tornar-se pai antes de completar 20 anos de idade, ressaltando a interdependência etária da parceira envolvida na reprodução e evidenciando que "[esta] definição deixa de lado considerações a respeito do relativismo social, cultural, étnico e psicológico da idéia geral de paternidade" (p. 70).

Reis (1997) afirma que somente a partir de 1980 começaram a despontar temas relacionados à paternidade, ainda que muito discretamente e adverte sobre a ocultação do papel da paternidade na problemática da gravidez adolescente.

As reações dos jovens diante de uma gravidez não planejada, bem como suas atitudes em relação a terem ou não filhos, são fortemente influenciadas por suas representações de paternidade e de papéis de gênero, segundo Domingues (1998). Nesse sentido é importante lembrar a importância dada por Medrado e Lyra (1999) à discussão com os jovens sobre a construção dos papéis de gênero em nossa sociedade. Os autores afirmam que

Investigar a temática e intervir na área da sexualidade e reprodução na adolescência significa discutir preconceitos e estereótipos arraigados e repensar a possibilidade de adoção de outros valores. Assim, aliada ao princípio do respeito pelas jovens gerações e à perspectiva de que a gravidez adolescente não é sempre indesejável, destaca-se o princípio da igualdade de oportunidades entre homens e mulheres em todos os âmbitos (p. 242).

Pode-se afirmar, então, que a compreensão da gravidez na adolescência, tanto no que se refere à maternidade quanto à paternidade, passa pela admissão de sua complexidade, sendo múltiplas as possibilidades de determinação. Para a ocorrência da gravidez na adolescência confluem diversos fatores culturais, sociais, afetivos e cognitivos, ou seja, tanto os fatores micro-sociais, referentes às condições objetivas e subjetivas da vida do sujeito em questão, quanto os fatores macro-sociais, como a classe social da qual ele é proveniente, fazem parte do processo.

Na medida em que os fatores sócio-culturais sejam considerados relevantes para a compreensão da gravidez na adolescência, uma forma privilegiada de abordar o tema da paternidade adolescente é através da consideração do que os jovens pais têm a dizer sobre o assunto, vez que seu relato permitirá a tradução da imagem, muitas vezes estereotipada, em expressão da vivência cotidiana.

Tanto os dados de Nóbrega (1995), como os de Amazarray, Machado, Oliveira e Gomes (1998), confirmam a importância de desvendar os valores além da imagem. Com Nóbrega (1995), descobrimos que, entre adolescentes das classes populares, a maternidade pode ser vista não como um problema, mas como uma solução. Já Amazarray et al. (1998), através do depoimento de seis mães adolescentes, mostraram que, apesar da dificuldade em conciliar trabalho, estudo e maternidade, as jovens consideram a experiência como muito positiva, tendo contribuído decisivamente para seu amadurecimento.

Para ingressar nesse campo de pesquisa tão pouco percorrido, e procurando contribuir com informações que possam ser úteis aos poucos serviços de assistência ao pai adolescente no Brasil, realizou-se uma pesquisa exploratória que teve como objetivos principais: descrever as mudanças ocorridas na vida de pais adolescentes e suas percepções sobre as conseqüências da paternidade e identificar o significado da paternidade e da maternidade para os jovens pais.

\section{Método}

Participaram do estudo oito rapazes com idades de 16 a 21 anos que se tornaram pais na adolescência e assumiram a paternidade, todos residentes na região da Grande Vitória/ES. Casualmente, ao verificar a inserção sócioeconômica dos participantes, percebeu-se que quatro deles eram de classe baixa e os outros quatro de classe média ${ }^{1}$.

Para a coleta de dados foi utilizada entrevista semiestruturada que abordou como temas principais: recebimento 
da notícia da gravidez da parceira; mudanças ocorridas a partir da gravidez; significado da paternidade e da maternidade; percepção da existência de apoio por parte dos pais a partir do período da gravidez; responsabilização acerca do uso de métodos contraceptivos e informação sobre o relacionamento com a mãe da criança.

A coleta de dados foi realizada em local e horário escolhidos pelos sujeitos. As entrevistas foram gravadas e posteriormente transcritas. Após a transcrição das entrevistas procedeu-se a uma leitura exaustiva de todo o material, utilizando técnicas de análise de conteúdo, e os relatos foram então reconstruídos segundo as unidades de significados apreendidas.

$\mathrm{Na}$ análise qualitativa considerou-se sempre o conjunto dos jovens, destacando as diferenças de acordo com as classes sociais somente quando pareceu relevante fazê-lo, sem a pretensão de estabelecer relações de causalidade.

\section{Resultados e Discussão}

Os resultados são apresentados a seguir de acordo com a seqüência das unidades de significado, com alguns recortes de transcrições de falas dos participantes para melhor ilustrá-los. Os jovens serão identificados por nomes fictícios, iniciados com a letra $\mathrm{B}$ para aqueles de classe baixa (Bruno, Bento, Benê e Bóris), e com a letra M para os de classe média (Mário, Marcos, Murilo e Manuel).

Na época da coleta de dados a situação dos participantes em relação à criação dos filhos e contatos com os mesmos pode ser descrita da seguinte forma:

- Bento, Benê, Bóris e Murilo moram com os filhos. Os três primeiros são casados com as mães das crianças e Murilo mora com seus pais.

- Os filhos de Bruno, Mário, Marcos e Manuel moram com a mãe e os avós maternos e os contatos pai-criança ocorrem principalmente nos fins de semana.

\section{Como aconteceu}

Sobre a ocorrência da gravidez, os relatos dos jovens são bastante preocupantes, mostrando desconhecimento de métodos contraceptivos e negligência quanto à prevenção de gravidez e DSTs. Evidenciaram também uma falsa noção de segurança, representada pelo relacionamento com virgens ou com parceiras fixas, ou pela crença em uma imunidade mágica.

Eu achava que esse tipo de coisa só acontecia com os outros. (Bruno e Marcos)

As informações fornecidas mostraram que a maior parte deles não tinha como hábito o uso de qualquer método contraceptivo antes da ocorrência da gravidez.
Somente dois relataram o uso de preservativo e de anticoncepcional por parte da parceira, interrompido por medo de engordar ou pelo desejo de engravidar.

O padrão de resposta mais comum a respeito da responsabilidade pela gravidez foi o de atribuição de culpa à namorada, ou porque queriam engravidar ou porque achavam que caberia a elas a prevenção.

Após a ocorrência da gravidez, constatou-se uma mudança neste aspecto. Os jovens passaram a usar algum tipo de contraceptivo. Ficou claro, porém, que o objetivo era a prevenção da gravidez, não havendo preocupação maior com sua saúde como um todo. Duas constatações inquietam: a reafirmação de que apesar das campanhas preventivas, os jovens continuam mantendo um padrão de comportamento sexual despreocupado com as DSTs; e a manutenção do antigo padrão de atribuição de responsabilidade reprodutiva à mulher, principalmente considerando a idade dos participantes.

\section{Reação à notícia}

A notícia da gravidez causou abalo e choque em Bento, Murilo e Manuel. Apareceram também sentimentos negativos como revolta, medo e vergonha nos relatos de Mário e Manuel. Bruno e Benê afirmaram ter sentido somente alegria, mas a reação apontada pela maioria frente à notícia da gravidez foi o sentimento de despreparo para lidar com a nova situação, presente entre todos os jovens de classe média e aparecendo também na fala de Bóris, expressando níveis de preocupação diferentes. Apesar de todos terem se referido à questão financeira, este tipo de preocupação surgiu com mais freqüência entre os mais pobres e só entre os jovens de classe média apareceram também inquietações relacionadas com sua imaturidade e inexperiência.

Não estava preparado pra ser pai não ... o que faltava era a preparação. Que preparação: ter um trabalho fixo, ter uma renda boa para tratar da família, isso aí. Pra mim era isso aí, os pensamentos que eu tinha era isso aí. Eu não tinha me preparado pra ser pai não. (Bóris)

Não, não tava preparado pra ser pai quando recebi a notícia... Falta ter uma relação melhor com meus amigos, uma relação melhor com as pessoas ... eu ter um pouco mais de cultura, um pouco mais de cabeça, um pouco mais de conhecimento. Eu não tenho muito o que passar para uma criança. (Marcos)

Esses resultados estão de acordo com aqueles encontrados por Domingues (1998) nos quais, para os adolescentes, outros fatores além dos econômicos contribuem na preparação para ter filhos, tais como maturidade, certa experiência de mundo e a presença de uma companheira estável. 


\section{Mudanças}

Os participantes referiram-se a mudanças em diferentes aspectos de suas vidas, destacando-se a inserção no mercado de trabalho. A maioria dos adolescentes começou a trabalhar como conseqüência da paternidade, mas Bento, Benê e Mário já trabalhavam. O trabalho afetou a vida dos jovens em relação aos estudos, ou porque tiveram que interrompê-los, ou porque passaram a se sentir divididos entre as duas atividades: uma - o trabalho - de fundamental importância para o cumprimento das responsabilidades daquele momento; outra - o estudo - considerada prioritária para a construção de um futuro melhor.

Tranquei a faculdade pra poder trabalhar... porque não só pela pensão que eu pago a minha filha, que não é um valor muito alto, mas pela responsabilidade que eu tenho que fazer alguma coisa, que eu tenho que crescer um pouco mais rápido... (Marcos)

A partir dos relatos foi possível apreender parte do que planejavam para o seu próprio futuro antes da paternidade inesperada. Observou-se que uma das opções de futuro, para os jovens de classe baixa, era permanecer no Exército após o cumprimento do serviço militar. Também tinham planos de emprego com boa remuneração, de constituir família e de adquirir uma boa casa. Entre os participantes de classe média estavam incluídos planos de realização de curso de nível superior e uma entrada mais tardia no mercado de trabalho.

Também foram referidas mudanças pessoais, sociais e afetivas e situações de constrangimento como as apontadas por Bóris e Marcos que foram alvos de cobranças e preconceito por causa da gravidez ou do casamento. Entre as mudanças relatadas a de maior impacto parece ter sido a perda de liberdade, mencionada por todos os sujeitos e traduzida pela diminuição nos contatos sociais e nos programas com os amigos.

Ah bicho, mudou foi a liberdade bicho. A liberdade. Você tem aquela liberdade assim de... mesmo que você... tem aquele, aquela mesma, uma rotina que você conversa com seus amigos, ali você se encontra, você se reúne. Quando você vai brincar ali na quadra de futebol, não pode que ela começa prender. Muda bastante. Você perde totalmente a liberdade que você tinha. (Bento)

Muda muita coisa, porque uma hora você tá novo, né, tá curtindo a sua vida e de repente você com uma notícia dessa que com 17 anos você vai ser pai, muda muita coisa... Você vai ter que criar, vai ter que sustentar e ao mesmo tempo também tira a sua liberdade de ser jovem, poder curtir.... (Mário)

Por outro lado, consideraram algumas mudanças positivas, como um ganho pessoal: aumento de responsabilidade, o amadurecimento e a relação afetiva com o filho, conforme mostram as falas seguintes:
Primeiro a gente fica mais responsável O que muda é a responsabilidade e a gente acaba se apegando ao filho. Aí a gente quer um futuro melhor. (Mário)

Tem uma colega minha que mexe com negócio de igreja, né. Ela percebeu isso em mim, que eu estou bem mais maduro e tal. Antes eu não ligava muito pra vida, né. Ela percebeu que 'Pô, você está bem maduro, tá novo ainda. Essa garotada nem pensa desse modo que você pensa'. Eu senti isso. (Murilo)

...quando eu só era namorado dela eu desviava meu dinheiro em bobagem, agora não, agora é só pegar para fazer o futuro da família, tá entendendo? Porque de primeira eu pegava o dinheiro comprava porcaria, gastava em um monte de bobagem... hoje é só levar pra dentro de casa mesmo e cuidar da família (Benê).

Parece que, como ocorreu com as jovens da pesquisa de Amazarray et al. (1998), apesar das dificuldades os pais adolescentes também encontram positividades na nova situação.

\section{O significado da paternidade e da maternidade}

A maioria dos jovens revelou satisfação com a condição de pai, mesmo levando em conta o aumento de responsabilidade, em alguns aspectos considerado positivo, e a perda da liberdade, e todos afirmaram apego aos filhos.

Para os sujeitos, pai é principalmente aquele que trabalha e sustenta o filho. Acompanhar, educar e preparar para a vida e para o futuro também apareceram nos relatos, bem como a idéia de que o pai deve ser presença constante na vida do filho. Alguns mencionaram que pai é aquele que dá carinho, amor e atenção e enfatizaram o surgimento de sentimentos de preocupação e responsabilidade.

Um bom pai tem que dar sempre atenção para a sua filha, sair com a filha, levar no parque, levar em vários lugares, dar carinho a ela, não deixar faltar nada dentro de casa. ...O filho pra mim é uma parte da gente. Filho dá trabalho, mas é bom. É bom ser pai. (Bóris)

Hoje você tem que trabalhar já pra menina porque você sabe que tem que dar leite, tem que comprar, não pode faltar nada porque pra você, você vive se ficar assim um dia sem comer nada, mas a menina, nessa parte de amamentação, de desenvolvimento é muito difícil. Ela tem que se alimentar direitinho. Eu me preocupo bastante com ela. (Bento)

Você vai ter que criar, vai ter que sustentar, você tem que dar dinheiro para ajudar a criança. Um bom pai pra mim ...é aquele que tá ali a toda hora, aquele que acompanha o filho no estudo, nas relações com as amizades, pra não ter má influência. Financeiramente também, tentando dar o de melhor pro filho. E sendo amigo dele. Isso pra mim é um bom pai. (Mário) 
Outro ponto de interesse aparece quando se percebe a ambigüidade dos sentimentos paternos entre alguns jovens: ao mesmo tempo em que afirmam o exercício da paternidade, demonstrado principalmente pela responsabilidade assumida, não se reconhecem como pais pela distância entre o modelo idealizado da figura paterna e seus sentimentos e práticas em relação aos filhos. $\mathrm{O}$ enleamento gerado pelo confronto com a paternidade foi mais claramente expresso pelos jovens que revelaram sentimentos de inadequação ao papel paterno, por se considerarem imaturos, inexperientes, sem condições de alcançar suas próprias expectativas e exigências em relação ao que é ser um pai, ou ainda por não terem conseguido elaborar integralmente as concretudes particulares dessa nova relação. A paternidade, inesperada e extemporânea, parece ter gerado o sentimento de terem sido privados da oportunidade de vivenciar etapas que consideravam cruciais para seu desenvolvimento pessoal.

Só fui conhecer a minha filha quando ela já tinha um mês de idade. Antes eu não podia assumir a minha filha, eu praticamente andava mais na sombra. Eu acho que primeiro você tem que conhecer a pessoa, depois namorar com a pessoa, depois existe o noivado, depois o casamento, depois a família. Ainda não me sinto preparado prá ser pai. Eu me vejo crescendo com ela... à medida que ela vai crescendo eu também vou crescendo com ela. E isso está sendo muito interessante pra mim. Ser um pai é ser um exemplo... pra você ter alguma coisa pra você passar para os outros você precisa ter experiência... Eu não podia ser pai naquela época. (Marcos)

Quando minha filha nasceu para te falar a verdade eu não esquentava muito a cabeça... não tinha aquela responsabilidade de pai. Eu gosto muito dela mas não me enxergo como pai não. Não entrava dentro de mim que eu era pai, parecia que ela era a minha irmã, eu gostava dela como minha irmã: será que um dia eu vou entender que ela é a minha filha? Que até agora eu não entendi isso aí, foi passando, foi começando a falar, começando a andar, aí você começa a absorver mais um pouquinho, começa a sentir mais: papai, tá me chamando de pai. Mas não adianta eu não enxerguei ainda que eu sou um pai. (Manuel)

Estas falas sugerem ainda que, enquanto para alguns jovens o processo de identificação com a paternidade é mais penoso e lentamente construído, para outros simplesmente não ocorre. Seria enganoso, no entanto, concluir que esses fatos são típicos da paternidade na adolescência, quando tão pouco ainda se sabe sobre o processo de construção da paternidade entre homens adultos.

Por um lado, a análise dos dados apontou o pai-provedor como mais emblemático na significação de paternidade, o que mostra como esse modelo ainda é forte em nossa sociedade, independente de classe social. Por outro lado, a partir dos relatos dos jovens foi possível apreender outros elementos de significação que indicam mudanças na dinâmica do processo parental. O pai também foi apontado como cuidador, como fator importante na educação dos filhos, como fonte de carinho e afeto.

Quanto ao significado da maternidade, apareceram padrões de conhecimentos e valores tradicionais. A mãe, para a maioria dos sujeitos, é aquela que dá amor, carinho e cuida do filho, tendo papel preponderante na vida da criança. Apenas Benê e Marcos afirmaram que pai e mãe têm a mesma importância para o desenvolvimento dos filhos.

Ser mãe, para eles, também significa abrir mão de tudo pelo filho, anular-se, sacrificar-se.

A mãe se pode ver, qualquer caso de justiça se um dia eu separar quem vai ganhar é a mãe porque o filho precisa muito mais da mãe, porque a mãe ela é a primeira coisa do mundo. Você pode ver a maioria dos filhos é ligado mais a mãe, porque a mãe é aquela pessoa que dá mais carinho. ( ) ... é muito fácil pro pai sair e ir viver, abandonar a criança. (Bento)

Eu enxergo que a mãe se é mãe ela tem que dispor das diversões, não que o pai não tenha que dispor, mas a mãe tem que dispor mais. Eu acho que o papel da mãe é mais influente para um filho que o de pai... Ela tem que viver para o filho, acho que é por aí, ela tem que viver para o filho. ( ) ... com certeza tem que cuidar mais que o pai. ( ) ... a mãe gerou dentro dela ... o amor da mãe é totalmente diferente do que o do pai. Então para mim a mãe tem que ser aquela mãe cuidadosa, presente, sempre presente. A mãe que tem, sei lá, que dispor das alegrias para ficar com o filho. Tem que dar o máximo dela para o filho. (Manuel)

Esta centralidade do papel materno já foi observada em trabalhos de diferentes autores (Nóbrega, 1997; Ramires, 1997; Rodrigues \& Trindade, 1999; Trindade 1998) mas, para a análise dos dados desta pesquisa, o trabalho de Nóbrega (1997) merece destaque. Entrevistando 21 adolescentes pertencentes à alta classe média urbana, 11 do sexo masculino e 10 do sexo feminino, para analisar valores sobre os papéis materno e paterno, a autora verificou que, apesar das indicações de mudanças relacionadas aos papéis sociais, com a valorização da participação feminina no espaço público, a visão tradicional se manteve quando o assunto se relacionava a filhos. Consideraram mais apropriado que a mulher cuidasse dos filhos e dela apenas se esperava a promoção de ajustes para conciliar vida doméstica e profissional.

\section{Práticas de paternagem}

Em consonância com o significado de provedor atribuído à paternidade, ser financeiramente responsável, pelo 
menos em parte, pela criação dos filhos, aparece freqüentemente como prática de paternagem e, em algumas falas, percebe-se o orgulho pela paternidade assumida.

Eu consegui quase há um ano atrás a paternidade de minha filha, ela já tem 2 anos... ela fica comigo nos finais de semana. Mas eu pago a pensão direitinho para ela. Foi tudo uma conquista minha, não foi nada de exigência da família dela. Tudo isso foi conquista minha para poder ver minha filha. (Marcos)

As principais atividades mencionadas pelos sujeitos, independentemente da condição de moradia, foram aquelas relacionadas com lazer e brincadeiras. Os filhos eram levados a passeios durante os finais de semana e, mesmo quando em casa, os relatos indicaram o brincar como principal atividade, enquanto os cuidados diários de alimentação e higiene ficavam como incumbências de mães e avós.

O papel da mãe é mais o de tomar conta, de cuidar. Aquilo que a sociedade já impõe já, né. Que a mãe é cuidar e o pai é brincar. Eu adoro ficar brincando com meu filho. Tomar conta meu, é brincar com ele, ficar brincando. Eu adoro brincar com ele. Dar banho não. Limpar fralda de vez em quando. (Murilo)

Mais uma vez é preciso cautela na análise destes resultados como próprios de pais adolescentes, lembrando ainda que quatro pais só mantinham contato com os filhos nos finais de semana, como já foi apontado. Entrevistando pais adultos Trindade et al. (1997) concluíram que as transformações no exercício da paternidade localizavam-se na existência de "...relações mais íntimas e expressivas entre pais e filhos", ainda distante da "...simetria das responsabilidades e das relações entre pais e mãe." (p. 220, grifos das autoras).

$\mathrm{O}$ que se pode perceber é que apesar da presença de significados e práticas que apontam a emergência de novas formas de expressão da paternidade, o cotidiano ainda se ancora na divisão tradicional de papéis. Os casos de doença, apontados como situações geradoras de preocupação e angústia, ilustram bem esta afirmação. As práticas descritas mostraram clara divisão de encargos: os pais compram remédios e acompanham ao médico, mas cuidar da criança é responsabilidade das mães e avós.

Conforme relato de alguns jovens, a deterioração do relacionamento com as mães das crianças vinha se transformando em obstáculo, impedindo contatos mais freqüentes e duradouros com os filhos o que pode ter reflexos na qualidade do relacionamento pai-criança.

Então eu tinha vontade de ver minha filha mas a mãe dela tava junto então eu não ia lá. (Manuel)
Eu sempre tenho que ligar antes para perguntar se vou poder ver minha filha, que horas que eu vou ter que deixar ... Até o momento que eu tiver condições, com certeza eu vou tirar a minha filha de lá prá criar ela sozinho. Eu adoro minha filha hoje em dia... Eu gostaria que minha filha ficasse mais tempo comigo. (Marcos)

\section{Apoio dos avós}

As práticas de paternagem guardam estreito vínculo com o papel dos avós na criação da criança. Os jovens mostraram-se gratos pelo apoio oferecido pelos avós, principalmente os avós maternos, com exceção de Murilo que só pode contar com seus pais. Foram referidos como apoio a ajuda financeira, tanto para lidar com a criança como para a manutenção do casal, os cuidados diários com a criança, possibilitando ou facilitando o estudo e/ou o trabalho dos pais, e o acompanhamento das atividades de lazer em fins de semana. Os avós também foram mencionados como fonte de orientação para a resolução de problemas corriqueiros com as crianças e, em alguns casos, eram considerados pelos jovens como aqueles que efetivamente criavam a criança.

\section{Algumas considerações}

A utilização da inserção social como referência teve como propósito assinalar possíveis caminhos para o desenvolvimento de pesquisas com amostras qualificadas para verificar diferenças de classe social relacionadas à paternidade na adolescência. Apesar de restritos, os dados apresentados apontam diferenças na forma como os jovens vivenciam a experiência de ser pai e a disparidade de contextos em que vivem pode ser tomada como um fator importante na produção das mesmas.

A presença de sentimentos negativos entre os jovens de classe média, por exemplo, pode refletir a existência de maior pressão social no contexto em que vivem. Por outro lado, somente sujeitos de classe baixa relataram sentimento de alegria, o que pode ter relação com o fato de que ter filhos já fazia parte dos seus planos para o futuro. Pode-se observar o mesmo em relação às mudanças ocorridas em relação a estudo e trabalho.

O nível de exigência apresentado pelos jovens participantes desta pesquisa para o que consideram um bom pai está em consonância com o sincretismo dos valores e crenças presentes no pensamento social, tanto no que diz respeito à paternidade como em relação à adolescência. Explicando, ao mesmo tempo em que se busca a concretização de novas formas de exercer a paternidade que se afastem do tradicional pai-provedor, o principal argumento imposto aos jovens como impeditivo de sua possibilidade de ser um bom pai é o financeiro, ou seja, 
ele não tem condição de assumir integralmente o papel de provedor. Somam-se a isso todas as representações a respeito da adolescência como fase de experimentação descompromissada, de fase de imaturidade ou de problemas a ela associados, como bem mostram Medrado e Lyra (1999). Parece que, no caso dos jovens participantes desta pesquisa, o estereótipo do descompromisso não se confirmou.

Quanto às mudanças referidas, apesar de ser comum o sentimento de perda de liberdade, observou-se que nem todas foram consideradas negativas. Isso reforça a idéia, também presente nos trabalhos de Amazarray et al. (1998) e Nóbrega (1995) com mães adolescentes, de que para os adolescentes nem sempre a paternidade é percebida como um desastre que comprometerá toda sua vida futura. Parece que este tipo de percepção circula mais entre os adultos, pais e profissionais. O que se viu entre os participantes desta pesquisa foi que procuraram se adaptar à nova situação, enfatizando os aspectos positivos, apesar das alterações que ocorreram em suas vidas. Nesse ponto, constatou-se a importância do apoio familiar encontrado pelos sujeitos como um fator importante a ser destacado.

O caráter exploratório deste trabalho bem como o reduzido número de participantes impõem limites à interpretação dos dados. Mesmo assim vale a pena ressaltar a importância que o conhecimento a respeito do significado de paternidade e de maternidade pode ter quando lidamos com situações como a focalizada no presente estudo. Viver a experiência de ser pai ou mãe no período da adolescência pode colocar os jovens em situação na qual se faz necessário o oferecimento de apoio institucionalizado na forma de programas de atendimento e orientação que envolvam tanto profissionais como a comunidade de uma forma mais ampla.

No entanto, o desvendamento de estereótipos e a desnaturalização dos processos de maternidade, paternidade e adolescência são de fundamental importância para a formação de profissionais comprometidos com a negação e a transformação de práticas excludentes.

Alguns estudos têm mostrado que ao mesmo tempo em que se fala de um "novo pai" emergindo na sociedade e começando a representar um outro parâmetro de paternidade, percebe-se também que muitas vezes "esta nova face da paternidade não é compreendida e nem estimulada por parte das mulheres e da equipe de profissionais da saúde" (Resende \& Alonso, 1995, p. 66).

Sobre esse aspecto, as reflexões de Trindade (1999) sobre "o significado social dos processos de maternidade e paternidade e seus entrelaçamentos no cotidiano de homens e mulheres" (p. 33) e das implicações deste significado para a formação e prática de profissionais de psicologia merecem aqui ser destacadas. Acompanhando as proposições da au- tora, argumenta-se que os serviços prestados e ações desenvolvidas em programas de atendimentos aos jovens pais e mães devem ser pautados pela conduta ética dos profissionais envolvidos, que implicaria no reconhecimento crítico de seu sistema de crença e valores. Só assim seria possível "respeitar o sujeito sem lhe impor suas concepções, muitas vezes tão naturalizadas que são percebidas como únicas e verdadeiras" (p. 38), minimizando o risco de estar tão somente reproduzindo o pensamento social dominante, naturalizando processos sociais, sem perceber que são "produto de uma história construída por práticas humanas passíveis de transformação" (Trindade, 1999, p. 38).

\section{Agradecimentos}

As autoras agradecem a participação de Rafael da Silveira Gomes e Thiago Drumond, bolsistas de Iniciação Científica/CNPq.

\section{Referências}

Amazarray, M. R., Machado, P. S., Oliveira, V. Z., \& Gomes, W. B. (1998). A experiência de assumir a gestação na adolescência: um estudo fenomenológico. Psicologia: Reflexão e Crítica, 11, 1-10.

Boyd, S. T. (1985). Study of the father - Research methods. American Behavioral Scientist, 29, 112-128.

BRASIL, Ministério da Saúde, Departamento de Informática do Sistema Único de Saúde (DATASUS), disponível no endereço eletrônico www.saude.gov.br.

Domingues, G. I. (1998). Varones adolescentes: los significados de la paternidad em la transición hacia los roles adultos. In E. D. Bilac \& M. I. B. Rocha (Orgs.), Saúde Reprodutiva na América Latina e no Caribe (pp. 237-260). Campinas: PROLAP, ABEP, NEPO/UNICAMP/ São Paulo: Ed. 34.

Lyra, J. L. L. (1997). Paternidade adolescente: uma proposta de intervenção. Dissertação de Mestrado não-publicada, Pontifícia Universidade Católica de São Paulo, São Paulo.

Lyra, J. L. L. (1998). Paternidade adolescente: da investigação à intervenção. In M. Arilha, S. G. U. Ridenti \& B. Medrado (Orgs.), Homens e masculinidades: outras palavras (pp. 185-214). São Paulo: ECO/Ed. 34.

Herrenkohl, E. C., Herrenkohl, R. C., Egolf, B. P., \& Russo, M. J.(1998). The relationship between early maltreatment and teenage parenthood. Journal of Adolescence, 21, 291-303.

Mackey, W. C. (1996). The american father: biocultural and developmental aspects. New York: Plenum.

Medrado, B., \& Lyra, J. (1999). A adolescência “desprevenida" e a paternidade na adolescência: uma abordagem geracional e de gênero. In $\mathrm{N}$. Schor, M. S. F. T. Mota \& V. C. Branco (Orgs.), Cadernos juventude, saúde e desenvolvimento (vol. 1, pp. 230-248). Brasília: Ministério da Saúde, Secretaria de Políticas de Saúde.

Nóbrega, N. P. (1995). Maternidade na adolescência: alienação e reprodução. Documenta, III(6), 63-76.

Nóbrega, N. P. (1997). O papel da parentalidade na construção do sujeito. In M. I. D'Avila Neto \& C. A. Garcia (Orgs.), Mulher: cultura e subjetividade. Coletâneas da ANPEPP, 1(7), 135-146.

Nock, S. L. (1998). The consequenses of premarital fatherhood. American Sociological Review, 63(2), 250-263 
Oliveira, M. W. (1998). Gravidez na adolescência: Dimensões do problema. Cadernos CEDES, 19(45), 48-70.

Ramires, V. R. R. (1997). O exercicio da paternidade hoje. Rio de Janeiro: Record: Rosa dos Tempos.

Reis, A. O. A. (1997) Opacidade e visibilidade da paternidade na reprodução adolescente. Revista Brasileira de Crescimento e Desenvolvimento Humano, 7(2), 69 - 76.

Resende, A. L. M. de \& Alonso, I. L. K. (1995). O perfil do pai cuidador. Revista Brasileira de Crescimento e Desenvolvimento Humano, 5(1/ 2), 66-81.

Rodrigues, M. M., \& Trindade, Z. A. (1999). Em nome do pai e do filho: relações afetivas e instrumentais. In P. R. Menandro, Z. A. Trindade \& E. B. Borloti (Orgs.), Pesquisa em Psicologia: recriando métodos (pp. 125-138). Vitória: Universidade Federal do Espírito Santo.
Trindade, Z. A., Andrade, C. A. \& Souza, J. Q. (1997). Papéis parentais e representações da paternidade: a perspectiva do pai. Psico, 28(1), 207222.

Trindade, Z. A. (1998). Concepções de maternidade e paternidade: o convívio atual com fantasmas do século XVIII. In L. de Souza, M. F. Q. de Freitas \& M. M. P. Rodrigues (Orgs.), Psicologia: Reflexões (Im)Pertinentes (pp. 129-155). São Paulo: Casa do Psicólogo.

Trindade, Z. A. (1999). Concepções arcaicas de maternidade e paternidade e seus reflexos na prática profissional. Interfaces, 2(1), 33-40.

Weinstein, E., \& Rosen, E. (1994). Decreasing sex bias through education for parenthood or prevention of adolescent pregnancy: A developmental model with integrative strategies. Adolescence, 29(115), 27-35.

Zeidi Araujo Trindade, doutora em Psicologia Experimental pela Universidade de São Paulo, é docente do Departamento de Psicologia Social e do Desenvolvimento e do Programa de Pós-Graduação em Psicologia da Universidade Federal do Espírito Santo.

Maria Cristina Smith Menandro, mestre e doutoranda do Programa de Pós-Graduação em Psicologia da UFES, é docente do Departamento de Psicologia Social e do Desenvolvimento da Universidade Federal do Espírito Santo.

Endereço para correspondência: [ZAT] Av. Mestre Álvaro, 448, Manguinhos, 29168-200, Serra, ES. Tel: (27)243.1534, Fax: (27)335.2501. E-mail: zeidi@globo.com. [MCSM] Rua Constante Sodré, 869, ap. 201, Praia do Canto, 29055-420, Vitória, ES. Tel: (27)225.7165, Fax: (27)335.2501. Email: crismenandro@uol.com.br. 